\title{
Management of acute paroxysmal supraventricular tachycardia in pregnancy
}

\author{
BRIAN PAHLOW, DO \\ ALAN K. GEISLER, DO \\ GEORGE H. DAVIS, DO
}

The treatment of paroxysmal supraventricular tachycardia (PSVT) in pregnancy is not unlike treatment for the general population. The physician should feel confident that the pharmacologic agents ordinarily used to treat this common problem in the general population are safe for both mother and fetus when administered under monitored conditions. In treating paroxysmal supraventricular tachycardia in pregnancy, when both vagal maneuvers and exhaustive medical therapy fail, synchronized, direct-current cardioversion is a safe and effective form of treatment.

(Keywords: Pregnancy, paroxysmal supraventricular tachycardia, arrhythmia, tachyarrhythmia, cardiac emergency)

Paroxysmal supraventricular tachycardia (PSVT), or paroxysmal atrial tachycardia as it is sometimes called, is a commonly encountered cardiac emergency in the general popu-

From the University of Medicine and Dentistry of New Jersey-School of Osteopathic Medicine, Stratford, where, at the time this article was written, Dr Pahlow was a fellow in cardiology; Dr Geisler is assistant professor of clinical medicine, Department of Cardiology; and $\mathrm{Dr}$ Davis was a member of the full-time faculty, Department of Obstetrics, Gynecology, and Perinatology. Currently, Dr Pahlow is in private practice in Salem, $\mathrm{NJ}$, and Dr Davis, in Barrington, NJ.

Reprint requests to Alan K. Geisler, DO, 301 South Central Plaza-Laurel Rd, Suite 3100, Stratford, NJ 08084-1504. lation. The type of treatment instituted and the urgency of its administration are dictated by the presence or absence of hemodynamic instability, which in turn is often directly dependent on the presence or absence of underlying cardiac dysfunction.

The incidence of PSVT in pregnancy is unknown, but it is by no means an uncommon event. This arrhythmia has been reported to increase in the third trimester. ${ }^{1}$ Although the comparatively young age and relative absence of significant heart disease in the pregnant population lends itself to a lower incidence of hemodynamic compromise, the fact remains that syncope, hypotension, angina pectoris, and heart failure do occur. The fetus is also at significant risk of incurring anoxic injury secondary to hypoperfusion. This makes constant fetal heart monitoring essential. ${ }^{2}$

Physicians are generally comfortable treating PSVT in the general population, but they may approach this problem with a great deal more hesitancy in pregnant patients. Two particularly anxiety-provoking questions physicians may ask themselves are: Is the treatment for this problem different in the pregnant population? What effect will the treatment have on the fetus?

It is the intent of this review to briefly examine the common causes of PSVT in pregnant women and to discuss the various modes of treatment and their effects on the mother and fetus. This discussion will help to answer the questions raised and to provide a greater 
sense of security for physicians faced with this dilemma.

\section{Initial assessment}

The initial evaluation of PSVT in the pregnant woman should begin with a complete history and physical examination. Excessive dietary intake of caffeine, alcohol, or tobacco, and the use of illicit drugs such as amphetamines or cocaine are all important secondary causes of PSVT. ${ }^{1}$ Excessive dosages of prescribed medications such as $\beta$-agonists, theophylline preparations, and thyroid replacements must also be considered. Underlying endocrine disorders, such as primary hyperthyroidism, or a pulmonary pathologic process, such as pulmonary embolus, must be considered and evaluated by routine laboratory tests such as arterial blood gas and thyroid function tests.

Physical examination of the pregnant patient during an episode of PSVT is of obvious importance but seldom enables the physician to determine a specific cause. Even the click and mid- to late-systolic murmur of mitral valve prolapse may often go undetected with the pulse at such rapid rates. Physical findings of tachypnea, cyanosis, hypotension, rales, or a third heart sound have obvious implications with regard to the need for urgent resolution of the arrhythmia.

\section{Classification}

The nomenclature used to classify these tachyarrhythmias is shrouded in confusion. Tachycardias demonstrating a narrow QRS complex with regular $R-R$ intervals and without evidence of preexcitation are grouped separately as paroxysmal atrial tachycardia or paroxysmal junctional, or nodal tachycardia. They are all, however, examples of paroxysmal supraventricular tachycardia. ${ }^{3}$

Of all the possible mechanisms responsible for a narrow complex tachycardia, paroxysmal atrioventricular (AV) (or nodal) reentrant tachycardia is by far the most common cause in pregnancy and in the general population..$^{1,4}$ In $90 \%$ of these cases, the tachycardia involves a circus rhythm confined entirely to the AV node and is composed of anterograde conduction to the ventricle over slow (alpha) fibers and retrograde conduction to the atrium over fast (beta) fibers.

The arrhythmia is initiated by a premature atrial complex that blocks conduction in the fast fibers. It thus establishes a pathway for reentry that uses the slower pathway for anterograde conduction and the fast pathway for retrograde conduction. Less commonly, reentry may likewise occur within the sinoatrial node or the atria, or it may involve accessory pathways to the ventricle or conduction system. ${ }^{3}$

Electrocardiographically, reentrant tachycardia in the AV node is characterized by a narrow QRS complex of 0.12 seconds or less, regular heart rates between 150 and 250 beats per minute, and abrupt onset and termination. ${ }^{4}$ Bar and colleagues ${ }^{5}$ reviewed the electrocardiographic criteria currently used in the differential diagnosis of narrow complex tachycardia. They found $\mathrm{P}$ wave location to be the most helpful tool among all criteria. In more than two thirds of the cases of AV nodal reentrant tachycardia reviewed, the $\mathrm{P}$ wave occurred simultaneously within the QRS complex. This finding was in direct contradistinction to PSVT involving accessory pathways in which the $\mathrm{P}$ wave was found to follow the QRS complex in the majority of cases.

Finally, there is the situation in which patients with PSVT have heart rates greater than 250 beats per minute. In these patients, the physician should suspect one of the preexcitation syndromes such as Wolff-ParkinsonWhite or Lown-Ganong-Levine. Standard firstline medical therapy with calcium-channel blockers or cardiac glycosides may be contraindicated in these cases. Such agents may actually promote conduction via the bypass tract, leading to higher heart rates and the potential for ventricular fibrillation. ${ }^{6,7}$

\section{Management}

\section{Vagal maneuvers}

Self-induced or physician-mediated attempts at increasing vagal tone should always form the first line of therapy in the management of hemodynamically stable PSVT in the pregnant patient. Unlike pharmacologic therapy, this form of intervention precludes potentially (continued on page 57) 


\section{THE RESPIRATORY SEASON MEANS}

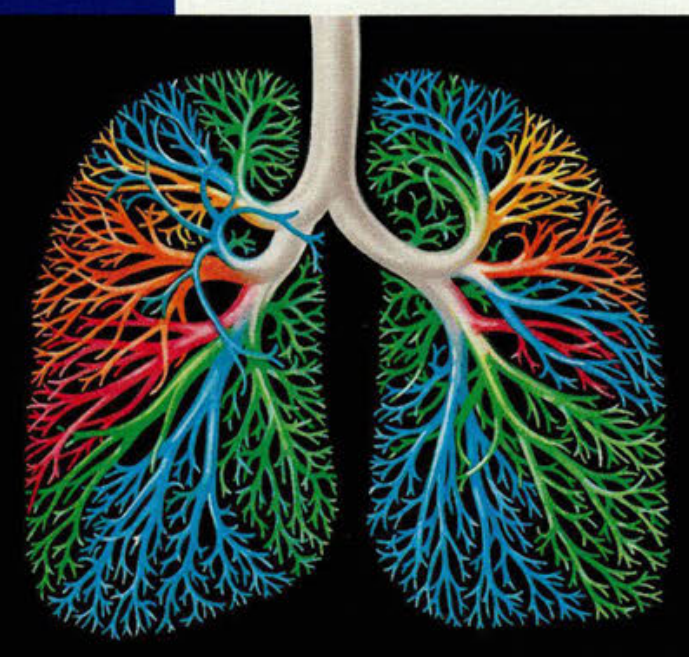

\section{TOUGH PATIENIS, TOUGH PATHOGENS...}




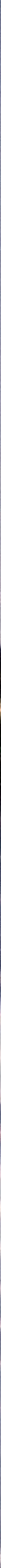




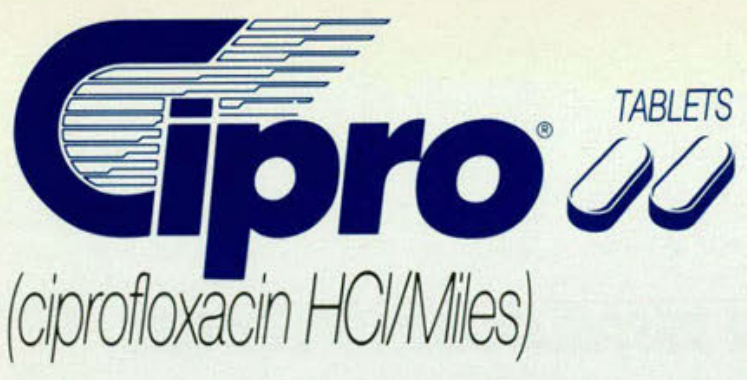

CIPRO * TABLETS

(ciprofloxacin $\mathrm{HCl} / \mathrm{Miles}$ )

BRIEF SUMMARY

CONSULT PACKAGE INSERT FOR FULL PRESCRIBING INFORMATION

INDICATIONS AND USAGE

Cipro* is indicated for the treatment of infections caused by susceptible strains of the designated microorganisms in

the conditions listed below: mirabilis. Pseudomonas aeruginesa. Haemophilus influenzae. Haemophilus parainfluenzae, and Streptococcus

Sneumoniae. Proteus mirabilis. Proteus vulgaris. Providencia stuartii. Morganella morganii. Citrobacter freundii. Pseudomonas aeruginosa. Staphylococcus aureus. Staphylococcus epidermidis, and Streptococcus pyogenes

Bone and Joint Infections caused by Enterobacter cloacae. Serrata marcescens, and Pseudomonas aeruginosa. Urinary Tract Infections caused by Escherichia colli. Klebsiella pneumoniae. Enterobacter cloacae. Serratia mar cescens. Proteus mirabilis. Providencia rettgeri. Morganella morganii. Citrobacter diversus. Citrobacter freundii. Pseudomonas aeruginosa. Staphylococcus epidermidis, and Streptococcus faecalis.

Infectious Diarmhea caused by Escherichia coli (enterotoxigenic strains). Campylobacter jejuni, Shigella flexneri, and Shigella sonnei" when ant bacterial therapy is indicated.

EHficacy for this organism in this organ system was studied in fewer than 10 infections. CONTRAINDICATIONS

A history of hypersensitivity to ciprofloxacin is a contraindication to its use. A history of hypersensitivity to other quinolones may also contraindicate the use of ciprofloxacin.

\section{WARNINGS}

CIPROFLOXACIN SHOULD NOT BE USED IN CHILDREN. ADOLESCENTS, OR PREGNANT WOMEN. The oral administration of ciprofloxacin caused lameness in immature dogs. Histopathological examination of the weight-bearing joints of these dogs revealed permanent lesions of the cartliage. Related drugs such as nalidixic acid, cinoxacin. and nortloxacin also produced erosions of cartlage of weight-bearing joints and other signs of arthropathy in immature animals of various species (SEE ANIMAL PHARMACOLOGY SECT PRECAUTIONS

General: As with other quinolones, ciprofloxacin may cause central nervous system (CNS) stimulation, which may General: As with other quinolones. Ciprofloxacin may cause centra nervous system (CNS) stimulation, which may fore, ciprofloxacin should be used with caution in patients with known or suspected CNS disorders, such as severe fore. Ciprofloxacin should be used with caution in patients with known or suspected CNS disorders, such as severe Anaphylactic reactions following the first dose have been reported in patients receiving therapy with quinolones. Some reactions were accompanied by cardiovascular collapse, loss of consciousness, tingling. pharyngeal or facia edema dyspnea. uticaria, and itching. Only a few patents had a history of hypersensitivity reaction. Anaphylactic edema, dyspnea. urticaria. and itching. Only a few patents had a history of hypersensitivity disctiontinued at the first reactions may require epinephrine and
sign of hypersensitivity or allergy

Sign of hypersensitivity or aliergy
Severe hypersensitivity reactions characterized by rash, fever, eosinophilia, jaundice, and hepatic necrosis with tatal outcome have been reported rarely (less than one per million prescriptions) in patients receiving ciprofloxacin along with other drugs. The possiblity that these reactions were related to ciprofloxacin cannot be excluded. Ciprofloxacin should be discontinued at the first appearance of a skin rash or any sign of other hypersensitivity reaction

Crystals of ciprofloxacin have been observed rarely in the urine of human subjects but more frequently in the urine of laboratory animals (SEE ANIMAL PHARMACOLOGY SECTION IN FULL PRESCRIBING INFORMATION. Crystaluria related to ciprofloxacin has been reported only rarely in man. because human urine is usually acidic.
Patients receiving ciprofloxacin should be well hydrated, and alkalinity of the urine should be avoided. The Patients receiving ciprofloxacin should be well

recommended daily dose should not be exceeded.
Ateration of the dosage regimen is necessary for patients with impairment of renal function (SEE DOSAGE AND Aiteration of the dos
ADMINISTRATION)

ADMINISTRATION). As with any potent drug. periodic assessment of organ
hematopoietic function, is advisable during prolonged therapy

Drug Interactions: As with other quinolones. concurrent administration of ciprofloxacin with theophylline may lead to elevated plasma concentrations of theophylline and prolongation of its elimination halif-life. This may result in increased risk of theophylline-related adverse reactions. If concomitant use can

theophylline should be monitored and dosage adjustments made as appropriate. Quinolones, including ciprofloxacin, have also been shown to intertere with
lead to reduced clearance of cafteine and a prolongation of its plasma half-life.

Antacids containing magnesium hydroxide or aluminum hydroxide may interfere with the absorption of ciprofloxacin resulting in serum and urine levels lower than desired; concurrent administration of these agents with ciprofloxacin should be avoided

Concomitant administration of the nonsteroidal anti-inflammatory drug fenbuten with a quinolone has been eported to increase the risk of CNS stimulation and convulsive sezures.

Probenecid interferes with the renal tubular secretion of ciprofloxacin and produces an increase in the level of ciprofloxacin in the serum. This should be considered if patients are receiving both drugs concomitantly,

As with other broad-spectrum antibiotics, prolonged use of cprofloxacin may result in overgrowth of nonsusceptble organisms. Repeated evaluation of the patient's condition and microbial susceptibility testing is essential. superinfection occurs during therapy, appropriate measures should be taken

Information for Patients: Patients should be advised that ciprofloxacin may be taken with or without meals. The preferred time of dosing is two hours after a meal. Patients should also be advised to drink fluids liberally and not take antacids containing magnesium or aluminum

Patients should be advised that ciprofloxacin may be associated with hypersensitvity reactions, even following a single dose, and to discontinue the drug at the first sign of a skin rash or other allergic reaction

Ciprofloxacin may cause dizziness or lightheadedness; therefore patients should know how they react to this drug before they operate an automobile or machinery or engage in activities requiring mental alertness or coordination Patients should be advised that ciprofloxacin may increase the effects of theophylline and caffeine

Carcinogenesis, Mutagenesis, Impairment of Fertility: Eight in vitro mutagenicity tests have been conducted with ciprofloxacin and the test results are listed below

Saimonella Microsome Test (Negative)

E. coli DNA Repair Assay (Negative)

Mouse Lymphoma Cell Forward Mutation Assay (Positive)

Chinese Hamster $\mathrm{V}_{79}$ Cell HGPRT Test (Negative)

Syrian Hamster Embryo Cell Transformation Assay (Negative)

Saccharomyces cerevisiae Point Mutation Assay (Negative)

Saccharomyces cerevisiae Mitotic Crossover and Gene Conversion Assay (Negative)

Rat Hepatocyte DNA Repair Assay (Positive)

Thus, two of the eight tests were positive, but the results of the following three in vivo test systems gave negative results:

Rat Hepatocyte DNA Repair Assay

Micronucleus Test (Mice)

ong-term carcinogenicity studies in rats and mice have been completed. After daily oral dosing for up to 2 years, there is no evidence that c profloxacin had any carcinogenic or tumorigenic effects in these species.

Pregnancy - Pregnancy Category C. Reproduction studies have been performed in rats and mice at doses up to 6 times the usual dalily human dose and have revealed no evidence of impaired fertility or harm to the fetus due to ciprofloxacin. In rabbits, as with most antimicrobial agents, ciprofloxacin ( 30 and $100 \mathrm{mg} / \mathrm{kg}$ orally) produced

\section{IN LOWER RESPIRATORY INFECTIONS \\ CIPRO MAKESA TOUGH THERAPEUTIC CHOICE EASIER.}

gastrointestinal disturbances resulting in maternal weight loss and an increased incidence of abortion. No teratogenicify was observed at either dose. After intravenous administration, at doses up to $20 \mathrm{mg} / \mathrm{kg}$, no maternal toxicity was produced, and no embryotoxicity or teratogenicity was observed. There are, however, no adequate and wellcontrolled studies in pregnant women. SINCE CIPROFLOXACIN, LIKE OTHER DRUGS IN ITS CLASS, CAUSES ARI Mursing Mothers: It is not known whether ciprofloxacin is excreted in human mik, however, it is known that ciprofloxacin is excreted in the mik of lactating rats and that other drugs of this class are excreted in human mik cecause of th and because of the potentia for serious adverse reactions tom ciprofloxacin in nursing intants. drug to the mother.

Prug to the mother Pediatric Use: Patients under the age of 18 were not included in the clinical trials of ciprofloxacin because in children or adolescents (SEE WARNINGS)

\section{ADVERSE REACTIONS} drug. Adverse events that were considered likely to be drug related occurred in $7.3 \%$ of courses, possibly related in $9.2 \%$, and remotely related in $3.0 \%$. Ciprofloxacin was discontinued because of an adverse event in $3.5 \%$ of courses. primarily involving the gastrointestinal s/ste

events typical of quinolones are italicized.
The most frequently reported events, drug related or not, were nausea $(5.2 \%)$, diarrhea $(2.3 \%)$, vomiting $(2.0 \%)$, abdominal pain/discomfort $(1.7 \%)$, headache $(1.2 \%)$, restlessness $(1.1 \%)$, and rash $(1.1 \%$,

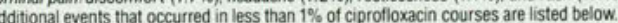

GASTROINTESTINAL: (See above), painful oral mucosa, oral candidiasis, dysphagia, intestinal perforation.

GENTTRAL NERVOUS SYSTEM: (See above), dizziness, lightheadedness, insomnia, nightmares, hallucina. tions, manic reaction, irritability, tremor, ataxia, convulsive seizures, lethargy, drowsiness, weakness, mal-

aise, anorexia, phobia, depersonalization, depression, paresthesia.
SKIN/HYPERSENSITIVITY: (See above), pruritus, urticaria, photosensitivity, flushing, fever, chills. angioedema, edema of the face, neck, lips, conjunctivae or hands. cutaneous candidiasis, hyperpigmentation. erythema nodosum.

Allergic reactions ranging from urticaria to anaphylactic reactions have been reported (SEE PRECAUTIONS). SPECIAL SENSES: blurred vision, disturbed vision (change in color perception, overbrightness of lights), decreased visual acuity, diplopia, eye pain, tinnitus. hearing loss, bad taste.

MUSCULOSKELETAL: joint or back pain, joint stiffness, achiness, neck or chest pain, flare-up of gout.

RENAL UROGENITAL: interstitial nephritis, nephritis, renal fallure, polyuria, urinary retention, urethral bleeding, vaginitis, acidosis.

CARDIOVASCULAR: palpitations, atrial flutter, ventricular ectopy, syncope, hypertension, angina pectoris. myocardial infarction, cardiopulmonary arrest, cerebral thrombosis.

RESPIRATORY: epistaxis, laryngeal or pulmonary edema, hiccough, hemoptysis, dyspnea, bronchospasm. pulmonary embolism.

Most of the adverse events reported were described as only mild or moderate in severity, abated soon after the drug was discontinued, and required no treatment.

In several instances, nausea, vomiting, tremor, restlessness, agitation, or palpitations were judged by investigators to be related to elevated plasma levels of theophylline possibly as a result of a drug interaction with ciprofloxacin.

Other adverse events reported in the postmarketing phase include anaphylactoid reactions. Stevens-Johnson syndrome, extoliative dermatits, toxic epidermal necrolysis, hepatic necrosis, postural hypotension, possible exacerbation of myasthenia gravis, confusion, dysphasia, nystagmus, pseudomembranous colitis, dyspepsia, flatulence, and constipation. Also reported were agranulocytosis; elevation of serum triglycerides, serum cholesterol, blood glucose, serum potassium; prolongation of prothrombin time; albuminuria; candiduria, vaginal candidiasis; and renal calculi (SEE PRECAUTIONS)

Adverse Laboratory Changes: Changes in laboratory parameters listed as adverse events without regard to drug relationship:

Hepatic-Elevations of: ALT (SGPT) (1.9\%), AST (SGOT) (1.7\%), alkaline phosphatase $(0.8 \%)$, LDH $(0.4 \%)$ serum bilirubin $(0.3 \%)$

Cholestatic jaundice has been reported.

Hematologic-Eosinophilia $(0.6 \%)$, leukopenia $(0.4 \%)$, decreased blood platelets $(0.1 \%)$, elevated blood platelets $(0.1 \%)$, pancytopenia $(0.1 \%)$.

Renal-Elevations of: Serum creatinine (1.1\%) BUN $(0.9 \%)$

CRYSTALLURIA, CYLINDRURIA, AND HEMATURIA HAVE BEEN REPORTED

Other changes occurring in less than $0.1 \%$ of courses were: Elevation of serum gammaglutamyl transferase, elevation of serum amylase, reduction in blood glucose, elevate

OVERDOSAGE

Information on overdosage in humans is not available. In the event of acute overdosage, the stomach should be Information on overdosage in humans is not avaliable. In the event of acute overdosage, the stomach should be emptied by inducing vomiting or by gastric lavage. The patient should be carefully observed and given supportive the body after hemodialysis or peritoneal dialysis.

\section{DOSAGE AND ADMINISTRATION}

The usual aduit dosage for patients with urinary tract infections is $250 \mathrm{mg}$ every 12 hours. For patients with complicated infections caused by organisms not highly susceptible, $500 \mathrm{mg}$ may be administered every 12 hours complicated infections caused by organisms not highly susceptible, $500 \mathrm{mg}$ may be administered every 12 hours. with $500 \mathrm{mg}$ every 12 hours. For more severe or complicated infections, a dosage of $750 \mathrm{mg}$ may be given every 12 hours.

The recommended dosage for infectious diarmea is $500 \mathrm{mg}$ every 12 hours.

In patients with renal impairment, some modification of dosage is recommended (SEE DOSAGE AND ADMINIS TRATION SECTION IN FULLL PRESCRIBING INFORMATION HOW SUPPLED

Cipro* (ciprofloxacin HCI/Miles) is avalable as tablets of $250 \mathrm{mg} .500 \mathrm{mg}$, and $750 \mathrm{mg}$ in bottles of 50 , and in UnitDose packages of 100 (SEE FULL PRESCRIBING INFORMATION FOR COMPLETE DESCRIPTION)

References: 1. Data on file, Miles Inc Pharmaceutical Division. 2. Barry AL, Jones RN, Thornsberry C, et al Antibacterial activities of ciprofloxacin, nortloxacin, oxolinic acid, cinoxacin, and nalidixic acid. Antimicrob Agents ciprofloxacin enoxacin and nalidixic acid anainst 423 strains of oram-negative rods and staphylococci isolated from intected hospitalised patients. JAntimicrob Chemother. 1986:17:63-67. 4. Van Caekenberghe DL. Paltyn SR. In vitro activity of ciprofloxacin compared with those of other new fluorinated piperazinyl-substituted quinolone derivatives. Antimicrob Agents Chemother. 1984,25:518-521

For further information, contact the Miles Information Service:

1-800-642-4776. In VA, coll collect: 703-391-7888.

COMMITTED TO THERAPEUTIC EFFICIENCY

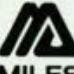

Miles Inc. 400 Morgan Lane 
serious side effects. This makes it an ideal initial therapeutic approach.

Valsalva's maneuver in which expiration is forced against a closed glottis, or the diving reflex, which is elicited by immersing the face in ice water while the breath is held, are two time-tested methods of increasing vagal tone at the $\mathrm{AV}$ node. ${ }^{8}$ When these measures fail or when the patient is unable to adequately perform these maneuvers, massaging the carotid sinus or gagging the patient are often effective means of converting the heart to normal sinus rhythm. ${ }^{9}$

\section{Drug therapy}

Obviously, if conservative measures designed to increase vagal tone fail, the physician has no choice but to prescribe medication in the attempt to slow the ventricular response and convert the heart to normal sinus rhythm. The choice of a particular drug will depend on its relative safety in pregnancy. No drug is completely safe. However, some agents clearly have a lower risk-to-benefit ratio than others. Verapamil hydrochloride, $\beta$-adrenergic blocking agents ( $\beta$-blockers), digoxin, and the type 1a antiarrhythmic agents are most commonly used for both acute and chronic conditions. Edrophonium chloride, ${ }^{10}$ a cholinesterase inhibitor, was widely used in the 1970 s for PSVT in the nonpregnant population. Because there are no reports concerning its safe use in pregnancy, it will not be included in the following discussion.

\section{Verapamil}

Studies to date have yet to substantiate the safety of verapamil in pregnancy when used during the critical phase of organogenesis. ${ }^{1,2}$ The drug, however, has an overwhelming record of effectiveness $(96 \%)$ in the treatment of PSVT. Because of this record and the fact that there is much evidence supporting its safety, verapamil is considered excellent firstline drug therapy. ${ }^{3,11}$ The use of verapamil is relatively contraindicated in pregnant women who have moderate to severe hypotention because of the drug's propensity for causing further maternal hypotension. To date, there have been no documented cases of fetal mor- bidity or mortality attributed to verapamil. ${ }^{1}$ Reports of safe and effective use of verapamil in the management of premature labor and even fetal supraventricular tachycardia in utero further support its use. ${ }^{12,13}$ The recommended dose is $0.075 \mathrm{mg} / \mathrm{kg}$ to $0.15 \mathrm{mg} / \mathrm{kg}$ administered intravenously (IV) over 1 to $3 \mathrm{~min}$ utes. This dose may be repeated in 20 to 30 minutes. ${ }^{11}$

\section{Beta-blockers}

Despite the fact that there has been no largescale controlled trial to evaluate $\beta$-blockers in the treatment of PSVT during pregnancy, a number of papers have been written regarding the use of these agents in the treatment of hypertension, ${ }^{14,15}$ thyrotoxicosis, ${ }^{16}$ and hypertrophic obstructive cardiomyopathy ${ }^{17}$ during pregnancy. Their excellent safety record and the rapid onset of action makes these agents desirable first- or second-line therapy for PSVT.

It is well known that $\beta$-blockers, selective or nonselective, readily cross the placenta and appear in the maternal and fetal circulations in significant concentrations. ${ }^{18}$ However, no report has ever linked a $\beta$-blocker to a fetal malformation. Conflicting reports have been written concerning an increased incidence of intrauterine growth retardation in mothers treated with propranolol hydrochloride. ${ }^{17,19} \beta$ Blockers can also cause a delay in the onset of spontaneous respirations based on their inhibition of the autonomic response to the stress of labor. Hypoglycemia of the newborn can occur, but the etiology of this is not clear. ${ }^{18}$

Once again, the presence of moderate to severe hypotension is a relative contraindication to the use of $\beta$-blockers. Propranolol is the $\beta$ blocker that has been most widely tested. It should be given IV in 1-mg to 2-mg increments every 15 to 20 minutes for the desired effect. When delivery is imminent, medical and obstetrical personnel should be prepared to intubate and ventilate the infant until spontaneous respirations are adequate.

\section{Cardiac glycosides}

Digoxin, the mainstay of glycoside therapy in the United States, is currently considered to (continued on page 61) 


\section{CHOLESTEROL CONTROL THAT'S CLEARLY UNTOUE..}
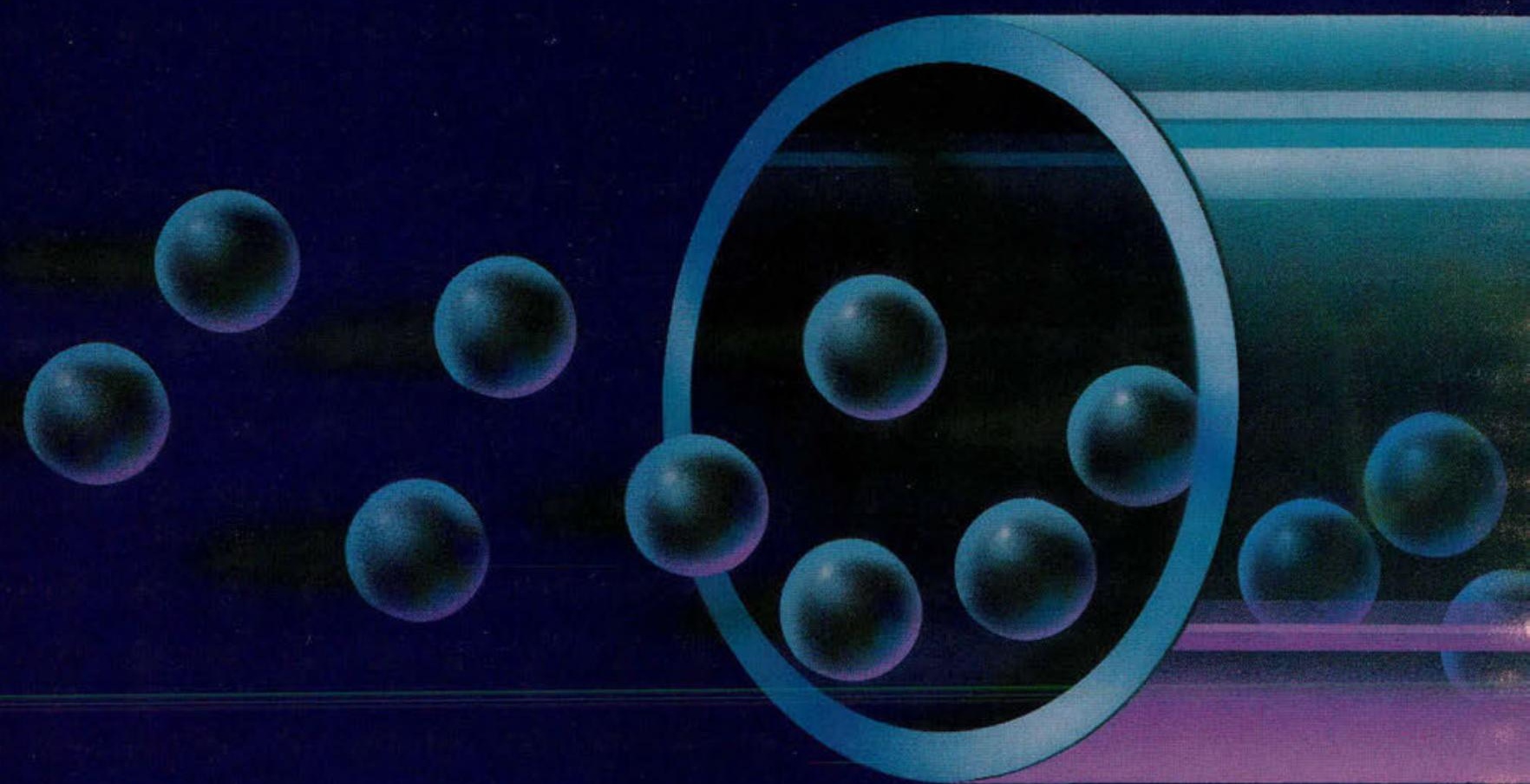

- Unique cholesterol-lowering action

-Lorelco ${ }^{\circledR}$ (probucol) enhances the clearance of

$L D L$-cholesterol from the bloodstream

-increases the removal of cholesterol from the body

\section{- Structurally distinct compound}

- Extensive clinical experience

-maintains lowered levels, as proven over a 12-year period'

-well tolerated and convenient for patients to use-just

one $500 \mathrm{mg}$ tablet b.i.d. with meals

Lorelco is indicated for the reduction of elevated serum cholesterol in patients with primary hypercholesterolemia, as an adjunct to diet.

Lorelco is not an innocuous drug and strict attention should be paid to the Indications,

Contraindications, Warnings, and Precautions sections of Prescribing Information.

- The effect of probucol-induced reduction of serum cholesterolor triglyceridelevels or reduction of $\mathrm{HDL}$-cholesterol

levels on morbidity and mortality due to coronary heart disease has not been established

1. Data on file, MERRELL DOW PHARMACEUTICALSINC. Cincinnati. Ohio $45242-9553$ 

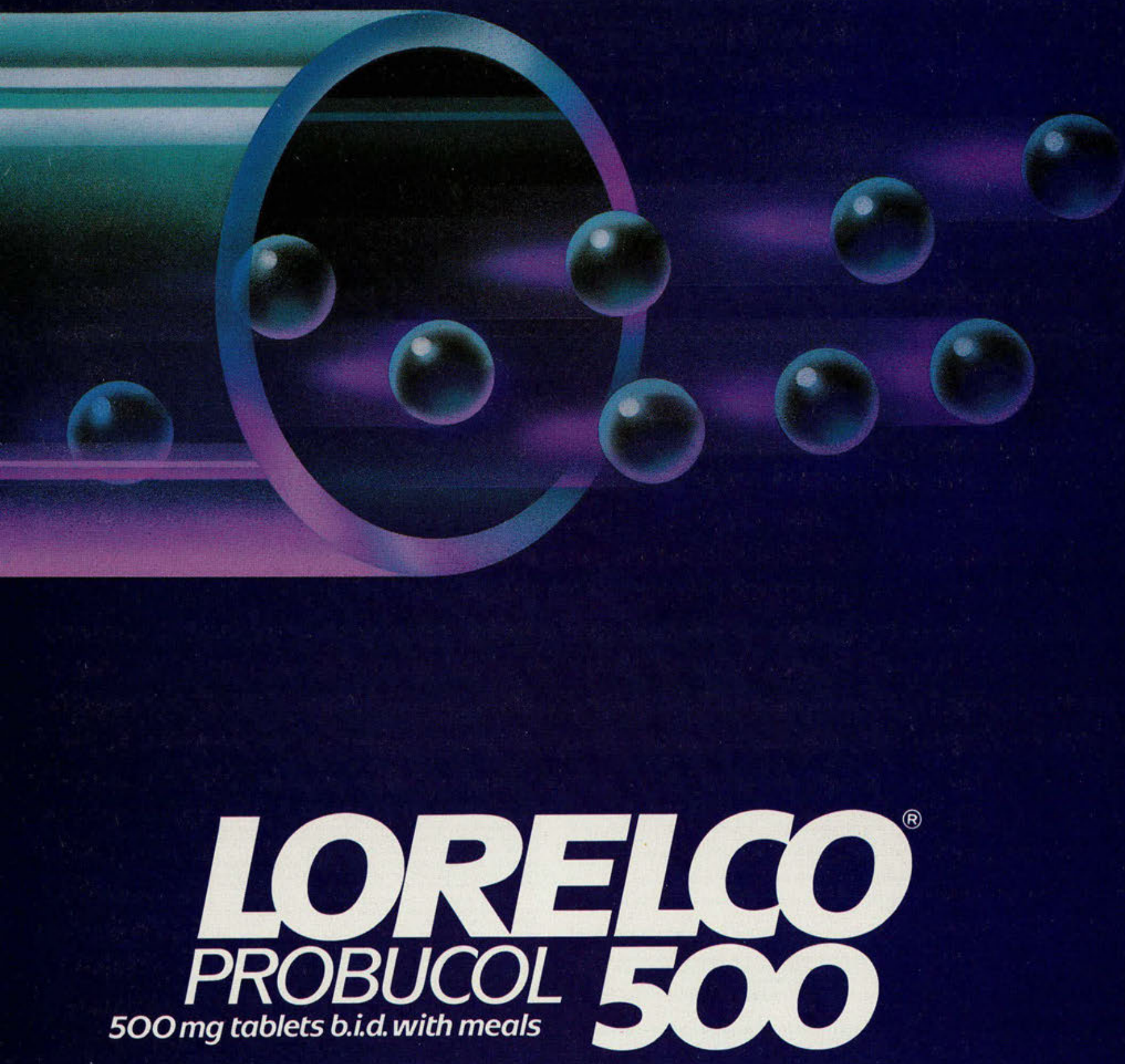

\section{Where the future of cholesterol control is moving}




\section{Lorelco ${ }^{\circledR}$ Tablets (probucol)}

\section{CAUTION: Federal law prohibits dispensing without prescription.}

DESCRIPTION: Lorelco (probucol) film-coated tablets for oral administration contain $250 \mathrm{mg}$ or $500 \mathrm{mg}$ of probucol per tablet. Each tablet also contains as inactive ingredients: corn starch, ethyicellulose, glycerin, hydroxypropyl cellulose and titanium dioxide Lorelico is an agent for the reduction of elevated serum cholesterol. The chemical name is $4.4^{\circ} \cdot 1(1-$ methylettylidene)bis(thio) bis 2,6 - bis(1.1-dimethylethyl) phenol]. Its chemical structure does not

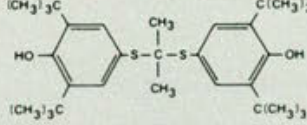

CLINICAL PHARMACOLOGY: Lorelco lowers total serum cholesterol and has relatively little effect on serum triglycerides. Patients responding to probucol exhibit a decrease in low-density lipoprotein (LDL) cholesterol. Cholesterol is reduced not only in the L.DL fraction, but also in the high-density lipoprotein (HDL) fraction with proportionately greater effect on the high-density por coronary heart disease. The risk of lowering $\mathrm{HDL}$-cholesterol while lowering $\mathrm{Lb} L$-cholesterol remains unknown. There is little

Studies on the mode of action of Lorelco indicate that $i$ increases the fractional rate of $L D L$ catabolism. This effect may be linked Loreico also exhibits inhibition of early stages of cholesterol biosynthesis and slight inhibition of absorption of dietary cholesterol. There is no increase in the cyclic precursors of cholestero, namely desmosterol a

Absorption of Lorelco from the gastrointestinal tract is limited and variable. When it is administered with food, peak blood levels
are higher and less variable. With continuous administration in a dosage of $500 \mathrm{mg}$ b.i.d. the blood levels of an individual gradually increase over the first three to four months and thereatter remain tairly constant. In 116 patients treated with Lorelco lor periods of three months to one year, the mean blood level was $23.6 \pm 17.2 \mathrm{mcg} / \mathrm{mL}( \pm S .0$.) ranging to $78.3 \mathrm{mcg} / \mathrm{mL}$.
Levels observed after seven years of treatment in 40 patients yielded an average value of $21.5 \pm 16.5 \mathrm{mcg} / \mathrm{mL}( \pm S .0$.$) ranging$ to $62.0 \mathrm{mcg} / \mathrm{mL}$. In a separale study in eight patients blood levels averaged $19.0 \mathrm{mog} / \mathrm{mL}$. at the end of $12 \mathrm{mmonths}$ of treatm
$\mathrm{Six}$ weeks after cessation of therapy, the average had tallen by $60 \%$. After six months, the average had fallen by $80 \%$. In December 1984, a National Institutes of Health Consensus Development Conference Panell concluded that lowering definitely
elevated blood cholesterol levels (specifically blood levels of LOL-cholesterol) will reduce the risk of heart attacks due to coronary heart disease. The effect of probucol-induced reduction of serum cholesterol or triglyceride levels, or reduction of INDICATIONS AND USAGE: Serious animal toxicity has been encountered with probucol. See WARNINGS and ANIMAL PHARMACOLOGY AND TOXICOLOGY sections. Probucol is not an innocuous drug and strict attention should be paid to the

Orug therapy should not be used for the routine treatment of elevated blood lipids for the prevention of coronary heart disease. tactor and should be addressed prior to any drug therapy. Physical exercise can be an important ancillary measure. Contributory disease such as hypothyroidism or diabetes melitus should be looked for and adequately treated. The use of drugs should be considered only when reasonable attempts have been made to obtain satisfactory results with nondrug methods. If the decision
ultimately is to use drugs, the patient should be instructed that this does not reduce the importance of adhering to diet. The selection of patients for cholesterol-lowering drug therapy should take into account other important coronary risk factors such as smoking, hypertension, and diabetes mellitus. Consideration should be given to the efficacy, saftety, and complian Lorelco may be indicated for the reduction of elevated serum cholesterol in patients with primary hypercholesterolemia (Types control of diabetes mellitus. Lorelco may be useful to lower elevated LDL-cholesterol that occurs in those patients with combined hypercholesterolemia and hypertriglyceridemia (Type IIb) due to elevation of both LDL and VLDL, but it is not indicated where hypertriglyceridemia is the abnormality of most concern. After establishing that the elevation in serum total
cholesterol represents a primary lipid disorder, 1 s should be determined that patients being considered for treatment with Lorelico have an elevated LOL-cholesterol as the cause for an elevated total serum cholesterol. This may be particularly relevant for patients with elevated triglycerides or with markedly elevated HDL-cholesterol values, where non-LDL fractions may contribute
significantly to total crolesterol levels without apparent increase in cardiovascular risk. In most patients, LDL-cholesterol may be estimated accor

$$
\text { LDL-cholesterol }=\text { Total cholesterol }-[(0.16 \times \text { triglycerides })+\text { HDL-cholesterol }]
$$

When total triglycerides are greater than $400 \mathrm{mg} / \mathrm{dL}$, this equation is less accurate. In such patients, LOL-cholesterol may be

It is not always possible to predict from the lipoprotein type or other factors which patients will exhibit favorable results. Lipid The effect of probucol-induced reduction of serum cholesterol or triglyceride levels, or reduction of HDL-cholesterol levels on

CONTRAINDICATIONS: (See also WARNINGS and PRECAUTIONS.) Lorelco is contraindicated in patients who are known to have a hypersensitivity to ti. Lorelco is contraindicated in patients with evidence of recent or progressive myocardial damage findings suggestive of serious ventricular arritythmias or with unexplained syncope or syncope
Loreico is contraindicated in patients with an abnormally long QT interval.

WARNINGS: SERIOUS ANIMAL TOXICITY HAS BEEN ENCOUNTERED WITH PROBUCOL IN RHESUS MONKEYS FED AN

\section{Prolongation of the QT interval can occur in patients on Loreico. Serious arrhythmias have been seen in} association with an abnormally long Qr.

1. Patients should be advised to adhere to a low cholesterol, low fat diet at the start of treatment with Lorelco and throughout the

2. An ECG should be done prior to starting treatment and repeated at appropriate intervals during treatment. If an abnormally
long OT interval is observed, the possible benefits and risks should be carefully considered before making a decision to Lorelco therapy should be discontinued or not started if the QT interval at an observed heart rate on a resting ECG is persistently more than one of the values listed below:

QT Interval in sec (15\% above the

\begin{tabular}{ccc}
\multirow{2}{*}{$\begin{array}{c}\text { Observed Heart Rate } \\
\text { (beats/min) }\end{array}$} & \multicolumn{2}{c}{$\begin{array}{c}\text { QT Interval in sec (15\% above the } \\
\text { upper limit of normal) }\end{array}$} \\
\cline { 2 - 3 } & Males & Females \\
\hline 40 & 0.56 & 0.58 \\
50 & 0.52 & 0.53 \\
60 & 0.49 & 0.50 \\
70 & 0.45 & 0.47 \\
80 & 0.43 & 0.44 \\
86 & 0.42 & 0.43 \\
100 & 0.40 & 0.41 \\
109 & 0.39 & 0.40 \\
120 & 0.37 & 0.38 \\
133 & 0.36 & 0.35
\end{tabular}

"Values calculated from Burch GE, Winsor T. A primer of electrocardiography. Philadelphia, PA: Lea and Febiger, 1958; p.
272 (tabie 6).

3. Patients developing unexplained syncope or syncope of cardiovascular origin should have Lorelco therapy discontinued and
should have ECG surveillance.

4. Drugs that prolong the OT interval are more likely to be associated with ventricular tachycardia after

a. An increase in the dose of the dru

Addition of a second drug that prolongs the QT interval (including tricyclic antidepressants, class I and III antiarritythmics.

and phenothiazines).

d. Severe bradycardla due to intrinsic heart disease or drug effects on the atrial rate (beta-blockers) or AV block (digoxin).

The use of Loreico in patients receiving any of these drugs should be based on the conclusion that

lowering outweigh the risk of serious arrhythmi

The following conditions should be resolved or corrected prior to initiation of therapy with Lorelco.

a. Hypokalemia

c. Severe bradycardia due to intrinsic heart disease or drug effects on the atrial rate (beta-blockers) or AV block (digoxin). PRECAUTIONS General: Before instituting therapy with Lorelco, adequate baseline studies should be performed to determine that the patient
has persistently elevated total and LDL-cholesterol levels representing a primary lipid disorder, and that the increased
cholesterol is not due to secondary conditions such as hypothyroidism, poorly controlled diabetes mellitus, obstructive liver disease, nephrotic syndrome, or dysproteinemias. Serum ipid levelis, including HOL-cholesterol, should be determined after an overnight fast betore treatment, during an adequate trial of diet and weight reduction therapy prior to addition of drug therapy. A A periadically during combined diet and drug therapy, including assessment during the first several months of drug treatment

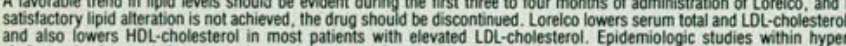
cholesterolemic populations have shown that serum HDL-cholesterol is an independent, inversely correlated, risk factor for coronary heart disease (see CLINICAL PHARMACOLOGY). Human studies which will attempt to confirm or deny the hypothesis
that drug-induced alteration in HOL-cholesterol affects cardiovascular risk are currently ynder evaluation. It is not known whether Lorelco-induced reduction of serum HOL-cholesterol will affect cardiovascular risk since no long-term, controlled
clinical trials of Loreico for the prevention of coronary heart disease, similar to the LRC-CPPT (see CLINICAL STUDDIES, have been performed. The probable benefits obtained from $\mathrm{LD} \mathrm{L}$-cholesterol reduction must be weighed against the possible risk of
reduction in $\mathrm{HDL}$-cholesterol when assessing the response of each patient receiving Lorelco treatment. If satisfactory lipid alteration is not achieved, the drug should be discontinued.
Information for Patients: The patient should be instructed to adhere to a prudent diet. Females should be cautioned agains
becoming pregnant for at least six months after discontinuing Lorelco and should not breast-feed their intants during therapy with Loreico.

Laboratory Tests: The physician should schedule periodic blood lipid determinations and periodic ECGs. (See WARNINGS.) levations of the serum transaminases (SGOT, SGPT), blilirubin, alkaline phosphatase, creatine phosphokinase, uric acid, blood urea nitrogen, and blood glucose above the normal range were observed on one or more occasions in various patients treated
with Lorelco. Most often these were transient and/ or could have been related to the patient's clinical state or other modes therapy. Although the basis for the relationship between Lorelco and these abnormalities is not firm, the possibility that some of these are drug related cannot be excluded. In controlled trials, the incidence of abnormal laboratory values was no higher in the

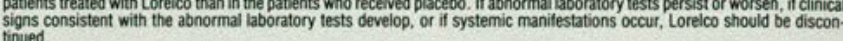

Drug Interactions: The addition of clofibrate to Lorelco is not recommended, since the lowering effect on mean serum levels lowering of HDL-cholesterol.

Neither oral hypoglycemic agents nor oral anticoagulan
agents is not usually modified when given with Lorelco.

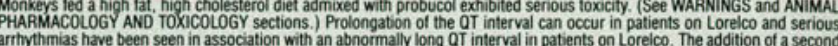
arrhythmias have been seen in association with an abnormally long at interval in patients on Lorelco. The addition of a second
drug that prolongs the OT interval (including tricyclic antidepressants, class I and lil antiarntiythmics, and phenothiazines) may drug that prolongs the QT interval (including tricyclic antidepressants, class I and lill ants
increase the risk of serious arrthythmia. (See CONTRAINDICATIONS AND WARNINGS.)

Carcinogenesis, Mutagenesis, Impairment of Fertility

In chronic studies of two years' duration in rats, no toxicity or carcinogenicity was observed. These results are consistent with Pregnancy

Pregnancy - Category B: Reproduction studies have been performed in rats and rabbits at doses up to 50 times the human dose, and have revealed no evidence of impaired fertility or harm to the fetus due to probucol. There are, however, no adequate and well-controlled studies in pregnant women. Because animal reproduction studies are not always predictive of human
response, this drug should be used during pregnancy only if clearly needed. Furthermore, if a patient wishes to become persistence of the drug in the body for prolonged periods. (See CLINICAL PHARMACOLOGY.)

abor And Delivery: The effect of Lorelco on human labor and delivery is unknown.

Nursing Mothers: It is not known whether this drug is excreted in human milk, but it is likely, since such excretion has been Pediatric Use: Satety and effectiveness in children have not been established.

ADVERSE REACTIONS

Gastrointestinal
diarmea or loose stools, flatulence, abdominal pain, nausea, vomiting, indigestion, gastrointestinal bleeding

Cardiovascular

prolongation of the QT interval on ECG, syncope, ventricular arrtythmias (ventricular tachycardia, torsades de pointes, Neurologic

s. paresthesia insomnia, tinnitus, peripheral neuritis

Hematologic

(a)

rash, pruritus, ecchymosis, petechiae, hyperhidrosis, fetid sweat

Genitourinary

impotency, noct
Ophthalmic

coniunctivitis, tearing, blurred vision

Endocrine

enlargement of multinodular goiter

dilosyncrasies

Other

diminished sense of taste and smell, anorexia, angioneurotic edema

DRUG ABUSE AND DEPENDENCE: No evidence of abuse potential has been associated with Lorelco, nor is there OVER OSYChological or physical dependence in humans.

OVERDOSAGE: There is a single report of a 15-kg, three-year-old, male child who ingested $5 \mathrm{~g}$ of probucol. Emesis was induced by ipecac. The child remained well, apart from a brief episode of loose stools and flatulence. No specific information
is avaliable on the treatment of overdosage with Lorelco and no specific antidote is avallable. Probucol is not dialyzable Treatment is symptomatic and supportive. Probucol has
animals the $L O$, (oral) is in excess of $5 \mathrm{~g} / \mathrm{kg}$ of body weight. DOSAGE AND ADMINISTRATION: For adult use only. The recommended and maximal dose is $1000 \mathrm{mg}$ daly

HOW SUPPLIED: $250 \mathrm{mg}$ round, white, film-COated tablets imprinted with either the DOW diamond trademark over the $500 \mathrm{mg}$ capsule-shaped, white, film-coated tablets, marked LORELCO 500 . Bottles of 100 (NDC 0068-0053-61)

Keep well closed. Store in a dry place. Avoid excessive heat. Dispense in weil-closed light-resistant containers with child-

ANIMAL PHARMACOLOGY AND TOXICOLOGY: In rhesus monkeys, administration of probucol in diets containing
unusually high amounts of cholesterol and saturated fat resulted in the death of four of eight animals after several weeks. unusually high amounts of cholesterol and saturated tat resulted in the death of four of eight animals after several weeks.
Premonitory syncope was frequently observed and was associated with a pronounced prolongation of the QT intervals $(30$ to Premonitory syncope was frequently observed and was associated with a pronounced prolongation of the QT intervals ( 30 to
$50 \%$ longer than that observed in untreated monkeys). Serum levels of probucol greater than $20 \mathrm{mcg} / \mathrm{mL}$ were generally
associated with some prolongation in the OT interval in the cholesterol-led monkey. A 55 msec or greater increase in of interval Irom control values was usually seen at $40 \mathrm{mcg} / \mathrm{mL}$ and above. Blood levels in humans receiving Lorelco average approximately
$20 \mathrm{mcg} / \mathrm{mL}$ and not uncormmonly reach levels of $40 \mathrm{mog} / \mathrm{mL}$ and higher. Rhesus monkeys ted normal (low fat chow and eceiving probucol three to thirty times the human dose equivalent achieved blood levels only one-third those of many human subjects. No adverse effects were detected in these monkeys over an eight-year period of continuous drug administration. In
another study in rhesus monkeys, an atherogenic diet was fed tor two years and daily treatment with probucol, separated in time monkeys, and less in the remaining animals. Marked prolongation of the Qf monkeys, and less in the remaining animals. Marked prolongation of the Qf cinterval in the ECG or syncopal behavior was never
observed over the entire one-year treatment period. Regression of gross aortic lesions comparable to that observed in a parallet
group of monkeys receiving cholestyramine was seen in animals receiving probucol. It should be emphasized that both HDLgroup of monkeys receiving cholestyramine was seen in animals receiving probucol. It should be emphasized that both HDL-
cholesterol and LDL-cholestercl were markedly reduced in this regression study. During the performance of a two-year chronic

study involving 32 probucol-treated dogs (beagles), there were 12 fatalities.
Subsequent experiments have indicated that probucol sensitizes the canine myocardium to epinephrine, resulting in ventricular
fibrillation in many dogs. Among the animal species in which probucol has been studied, the dog is peculiar with respect to the fibrillation in many dogs. Among the animal species in which probucol has been studied, the dog is peculiar with respect to the
phenomenon of sudden death due to the sensitization of the myocardium to epinephrine. In contrast to findings in the dog. injections of epinephrine to probucol-treated monkeys did not induce ventricular fibrillation.

In other studies, monkeys were given probucol either before and after, or only after myocardial infarction was induced by coronary artery ligation. In these studies, there was no difference between probucol-and placebo-
either survival or detailed blind quantitation of myocardial changes (gross and histopathologic).

Probucol has shown no identifiable toxicity in mice and rats. In these animals, the LDSO (oral) is in excess of $5 \mathrm{~g} / \mathrm{kg}$ of bocy weight. In chronic studies of two years duration in rats, no toxicity or carcinogenicity was observed.

From studies in rats, dogs, and monkeys, it is known that probucol accumulates slowly in adipose tissue. Approximately $90 \%$ of probucol administered orally is unabsorbed. For that which is absorbed, the biliary tract is the major pathway for clearance from Myocardial injury was produced in various groups of rats by one of the following procedures: aortic coarctation, coronary
ligation, or cobalt or isoproterenol injection. After probucol administration, no deleterious effects related to treatment occurred igation, or cobalit or isoproterenol injection. After probucol administration, no

Probucol was administered to minipigs beginning ten days before ligation of coronary artery and continued for 60 days after
surpery Challenge with epinephrine at the end of 60 days tailed to induce ventricular fibrilation in any of the coronary-igated surgery. Challenge with ep
probucol-treated minipigs

CLINICAL STUDIES: In a multicenter, randomized, double-blind study, the LRC-CPPT, ${ }^{3}$ hypercholesterolemic patients treated with an oral bile acid sequestrant (cholestyramine) and a cholesteroi-lowering diet experienced average total and LDL
cholesterol reductions greater than those obtained in the placebo group treated with diet alone. The cumulative seven-year incidence of the primary end point-combined incidence of definite $\mathrm{CHD}$ death and/or definite nontatal myocardial intarctionwas $7 \%$ in the cholestyramine group and $8.6 \%$ in the placebo group. This was a $19 \%$ reduction in risk ( $\mathrm{P}$ less than 0.05 , single
tail test) of the primary end point reflecting a $24 \%$ reduction in definite CHD death and a $19 \%$ reduction in nontatal myocardila

The subjects included in the study were middle-aged men ( 35 - 59 years old) with serum cholesterol levels at least $265 \mathrm{mg} / \mathrm{dL}$ and hypercholesterolemic population not studied.

The bile acid sequestrant, cholestyramine, was used in the above trial. Caution should be exercised in extrapolating these results

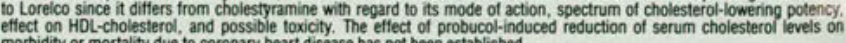
REFIidity or mor

1. Consensus Development Panel. Lowering blood cholesterol to prevent heart disease. JAMA. 1985; 253-2080-2086. . Fredricsson DS, Levy RI L Lees RS. Fat transport in lipoproteins - an integrated approach to mechanisms and disorders. N
Engi J Med. $1967 ; 276: 34.44$. 3. The Lipid Research Clinics Program. The Lipid Research Clinics coronary primary prevention trial results: I. Reduction in
incidence of coronary heart disease. JAMA. 1984; 251:351-364. Product Information as of June, 1988 
be safe for use in pregnancy. ${ }^{2}$ However, for the emergent treatment of PSVT in the pregnant woman, its relatively slow onset of action makes it less desirable in the treatment of acute PSVT. For the hypotensive pregnant patient with PSVT, IV digoxin may be considered the drug of choice because hypotension is not one of its common side effects.

Digoxin is freely transferred across the placenta, ${ }^{20}$ but, to date, it has not been shown to be teratogenic. Furthermore, no adverse effects, other than an increased incidence of prematurity, have been seen in the newborn when digoxin is administered to the mother at therapeutic levels. ${ }^{21}$ An entirely different picture of fetal risk arises in the face of digitalis toxicity. Reports of miscarriage and sudden fetal death are not uncommon in this setting. ${ }^{22,23}$ A loading dose of $1 \mathrm{mg}$ to $1.5 \mathrm{mg}$ of digoxin administered IV over 24 hours may be used short term to control the ventricular response. Pregnant patients, however, may require higher maintenance doses due to the normal increase in the glomerular filtration rate that accompanies pregnancy. ${ }^{24}$

Digoxin remains a safe and effective treatment mode for the short-term management of PSVT, but its narrow therapeutic index and potential for toxicity make it less than desirable for long-term use in the pregnant patient.

\section{Type 1a antiarrhythmic drugs}

Quinidine sulfate, procainamide hydrochloride, and disopyramide phosphate have all been proved effective in the treatment of PSVT. ${ }^{1}$ Unfortunately, only procainamide is available in a safe intravenous form for shortterm therapy. Although adverse effects on the fetus have been documented to occur with any of these agents, no adequate clinical or epidemiologic studies have been completed to date. ${ }^{2,25}$ In addition to the well-known cardiac and noncardiac side effects of these drugs, both quinidine and disopyramide have been reported to cause premature labor. ${ }^{26,27}$ As a group, these medications are of greatest value for maintenance therapy. Their use in pregnancy should be reserved for only the most refractory arrhythmias.

\section{Electric cardioversion}

The indications for synchronized, direct-current (DC) cardioversion in the pregnant woman with PSVT are identical to those for the general population. Evidence of syncope, hypotension, angina pectoris, or pulmonary edema mandates immediate conversion to normal sinus rhythm before any drug is administered. ${ }^{3}$ Also, in patients in whom all of the aforementioned pharmacologic agents fail, DC cardioversion must be considered even in the absence of hemodynamic compromise.

Since the introduction of electric cardioversion in 1962, there have been several reported cases of its use in pregnancy. The rhythm disturbances have ranged from PSVT to ventricular fibrillation, and the gestational ages of the fetuses at the time of cardioversion have ranged from 7 to 36 weeks. ${ }^{28}$

Electric cardioversion during pregnancy has never been shown to adversely affect the fetus in the short term, and no permanent fetal abnormalities have ever been detected. Fetal heart monitoring during and after cardioversion has revealed a decrease in fetal heart rate and a transient loss of the normal beat-tobeat variability in a number of cases. ${ }^{28}$

The proper use of DC cardioversion is not the subject of this article, but it would be well to mention that there are three principles to which one must adhere in following this procedure: (1) The shock must be synchronized with the mother's QRS complex in order to avoid the "R-on-T" phenomenon and subsequent induction of ventricular fibrillation. (2) If time allows, the patient must be properly sedated. (3) The initial energy delivered should be as small as possible (in the range of $50 \mathrm{~J}$ ) and increased thereafter in 50- to $100-\mathrm{J}$ increments until successful cardioversion is attained ${ }^{3}$ Also, the physician must be prepared to intubate the patient and temporarily pace the heart following cardioversion should the need arise.

\section{Summary}

The treatment of PSVT in the pregnant patient is similar to treatment of PSVT in the general population. Physicians encountering pregnant patients with PSVT need to under- 
stand that those measures that are effective in the general population can be safely used in the pregnant patient under monitored conditions. The approach should be systematic. Hemodynamic compromise usually warrants electric cardioversion in a closely monitored setting. Otherwise, the initial treatment should begin with vagal maneuvers followed by pharmacologic therapy. Such therapy may include the use of verapamil, $\beta$-blockers, digoxin, or type 1a antiarrhythmic agents. Physicians must be aware of the risk-to-benefit ratios of these drugs in the pregnant patient. Communication lines between the obstetrician and the cardiologist must also be established and maintained during PSVT episodes and, indeed, throughout the pregnancy.

1. Rotmensch H, Rotmensch S, Elkayam U: Management of cardiac arrhythmias during pregnancy. Drugs 1987;33:623-633.

2. Rotmensch H, Elkayam U, Frishman W: Antiarrhythmic drug therapy during pregnancy. Ann Intern Med 1983;98:487497.

3. Braunwald E: Heart Disease. Philadelphia, WB Saunders Co, 1984, pp 702-707.

4. Keefe D, Miura D, Somberg J: Supraventricular tachyarrhythmias: Their evaluation and therapy. Am Heart $J$ 1986;111:11501161.

5. Bar F, Brugada P, Dassen W, et al: The differential diagnosis of tachycardia with narrow QRS complex. Am J Cardiol 1984;54:555-560.

6. Gulamhusein S, Ko P, Carruthers G, et al: Acceleration of the ventricular response during atrial fibrillation in the WolffParkinson-White syndrome after verapamil. Circulation 1982;65:348-354.

7. Wellens HJ, Durrer D: Effect of digitalis on atrioventricular conduction and circus-movement tachycardias in patients with Wolff-Parkinson-White syndrome. Circulation 1973;47:12291233. 8. Valladares B, Lemberg L: Use of the diving reflex in paroxysmal atrial tachycardia. Heart Lung 1983;12:202-205.

9. Waxman MB, Wald RW, Sharma AD, et al: Vagal techniques for termination of PSVT. Am J Cardiol 1980;46:655-664.

10. Frieden J, Cooper J, Grossman J: Continuous infusion of edrophonium (Tensilon) in treating supraventricular arrhythmias. Am J Cardiol 1971;27:294-297.

11. Klein V, Repke J: Supraventricular tachycardia in pregnancy: Cardioversion with verapamil. Obstet Gynecol $1984 ; 63(3): 16 \mathrm{~s}-18 \mathrm{~s}$.

12. Wolff F, Breuker KH, Schlenkser KH, Bolte A: Prenatal diagnosis and therapy of fetal heart rate anomalies with a contribution on the placental transfer of verapamil. J Perinat Med 1980;8:203-208.

13. Ulmsten U: Inhibition of myometrial hyperactivity by calcium antagonists. Dan Med Bull 1979;26:125-126.

14. Tcherdakoff PH, Colliard M, Berrard E, et al: Propranolol in hypertension during pregnancy. $\mathrm{Br}$ Med J 1978;2:670.

15. Bott-Kanner G, Schweitzer A, Reisner SH, et al: Propranolol and hydralazine in the management of hypertension in pregnancy. Br J Obstet Gynecol 1980;87:110-114.

16. Langer A, Hung CR, McAnulty A, et al: Adrenergic blockade: A new approach to hyperthyroidism during pregnancy. $\mathrm{Ob}$ stet Gynecol 1974; 44:181.

17. Turner GM, Oakley, CM, Dixon HG: Management of pregnancy complicated by hypertrophic obstructive cardiomyopathy. Br Med J 1968;4:281-284.

18. Cottrill CM, Mcallister R, Gettes L, et al: Propranolol therapy during pregnancy, labor and delivery. J Pediatr 1977;91:812814.

19. Eliahou HE, Silverberg DS, Reisen E, et al: Propranolol for the treatment of hypertension in pregnancy. Br J Obstet Gynecol 1978;85:431-436.

20. Soyka LF: Digoxin: Placental transfer, effects on the fetus, and therapeutic use in the newborn. Clin Perinatol 1975;2:23-25. 21. Weaver JB, Pearson JF: Influence of digitalis on time of onset and duration of labor in women with cardiac disease. $\mathrm{Br}$ Med $J$ 1973;3:519-520.

22. Potondi A: Congenital rhabdomyoma of the heart and intrauterine digitalis poisoning. J Forensic Sci 1967;11:81-88.

23. Sherman JL, Locke RV: Transplacental neonatal digitalis intoxication. Am J Cardiol 1960;6:834-837.

24. Rogers MC, Willerson JT, Goldblatt A, et al: Serum digoxin concentrations in the human fetus, neonate, and infant. $N E n g l$ $J$ Med 1972;287:1010-1013.

25. Tamari I, Eldar M, Rabinowitz B, et al: Medical treatment of cardiovascular disorders during pregnancy. Am Heart $J$ 1982;104:1357-1363.

26. Hill L, Malkasian G: The use of quinidine sulfate throughout pregnancy. Obstet Gynecol 1979;54(3):366-368.

27. Leonard R, Braun T, Levy A: Initiation of uterine contractions by disopyramide during pregnancy. $N$ Engl $J$ Med 1978;299:84-85.

28. Meitus M: Fetal electrocardiography and cardioversion with direct current countershock. Dis Chest 1965;48:324-325. 
"I feel like I'm about to die...." 


\section{PANIC DISORDER}

\section{A DISEASE WITH}

Panic attacks are discrete, time-limited episodes that are characterized by a sudden, unexpected, and often overwhelming feeling of terror and intense fear, accompanied by severe physical symptoms. Later in the course of the disturbance, certain situations may become associated with having a panic attack. Many patients believe they are experiencing a heart attack or other life-threatening event and seek emergency attention.

Recent NIMH epidemiologic survey data estimate the lifetime prevalence of panic disorder at $1.6 \%$ of the general population.'

\section{DIAGNOSING PANIC DISORDER}

A diagnosis of panic disorder, according to the DSM-III-R, ${ }^{2}$ requires that a patient experience at least four panic attacks within a 4-week period or one or more attacks followed by a month of persistent fear of having another attack. 


\section{MANY DISGUISES}

Panic attacks involve four or more of the following characteristic associated symptoms (see Table).

These symptoms develop suddenly, with no apparent organic cause, and build in intensity within 10 minutes of the onset of the first symptom.

\section{Symptoms associated with panic attacks ${ }^{2}$}

- Tachycardia or palpitations

- Chest pain or discomfort

- Sweating

- Shortness of breath (dyspnea) or smothering sensations

- Flushes (hot flashes) or chills

- Dizziness, unsteady feelings, or faintness

- Nausea or abdominal distress

- Choking

Trembling or shaking

- Depersonalization or derealization

- Numbness or tingling sensations (paresthesias)

- Fear of dying

- Fear of going crazy or losing control

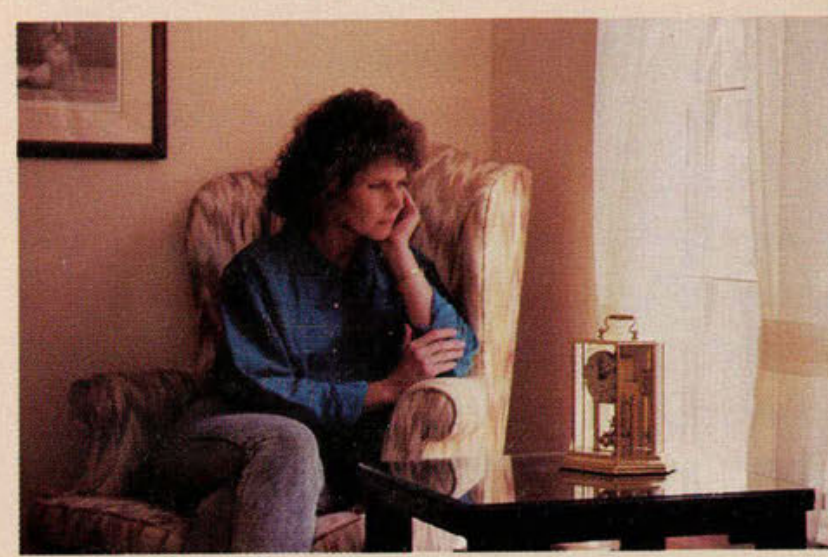

PANIC DISORDER AND PHOBIC AVOIDANCE

Most cases of panic disorder are accompanied by some degree of agoraphobia-the fear of being in places or situations from which escape might be difficult (or embarrassing) or in which help might be unavailable in the event of a panic attack. This fear often causes the panicdisorder patient to restrict daily activities dramatically, occasionally to the point of never leaving home. 


\section{PANIC DISORDER}

\section{A NEW INDICATIOI}

The effectiveness of XANAX Tablets (alprazolam) for the treatment of panic disorder with or without agoraphobia was conclusively demonstrated in three short-term, placebo-controlled trials (up to 10 weeks); however, patients with panic disorder have been treated successfully for up to 8 months. The largest of these studies, the Cross-National Collaborative Panic Study, involved more than 500 patients in eight centers in the United States, Canada, and Australia. ${ }^{3}$

\section{XANAX USUALLY BLOCKS PANIC ATTACKS WITHIN 1 WEEK} Percentage of patients free of panic attacks ${ }^{3}$

WEEK 1

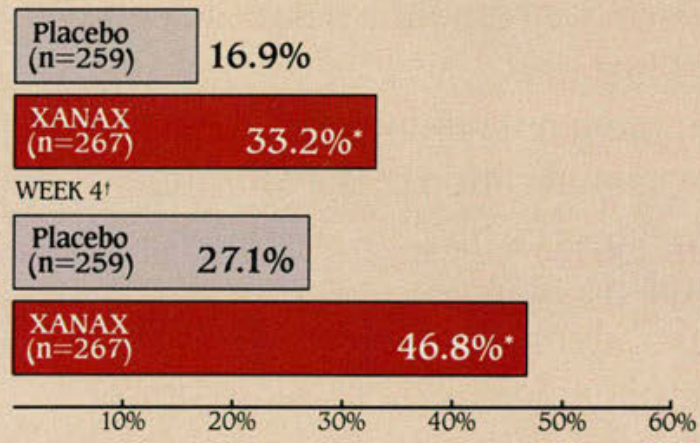

$-p<.001$

$\nmid$ End-point analysis involving all patients 


\section{OR XANAX ${ }^{\circ}$ TABLETS}

XANAX produced significant relief from panic attacks compared with placebo by the end of the first week of therapy.

\section{XANAX REDUCES PHOBIC AVOIDANCE}

In the same multicenter study, XANAX was significantly more effective than placebo in reducing overall phobic symptoms, as measured on an 11-point physician assessment scale.

\section{Mean overall phobic-symptom rating ${ }^{3 *}$}

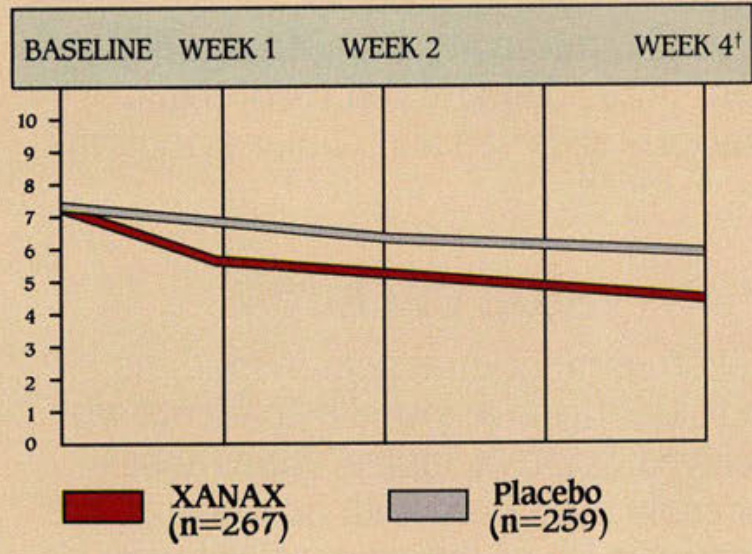

\section{XANAX REDUCES SOCIAL AND WORK DISABILITY}

When patients in the Cross-National Collaborative Panic Study were asked to indicate the extent to which their social life and work abilities were impaired by their disorder on a scale from $\mathrm{O}$ (not at all) to 10 (very severely, cannot work), those who received XANAX showed significantly greater improvement than those who took placebo.

\section{Mean work impairment rating ${ }^{3 *}$}

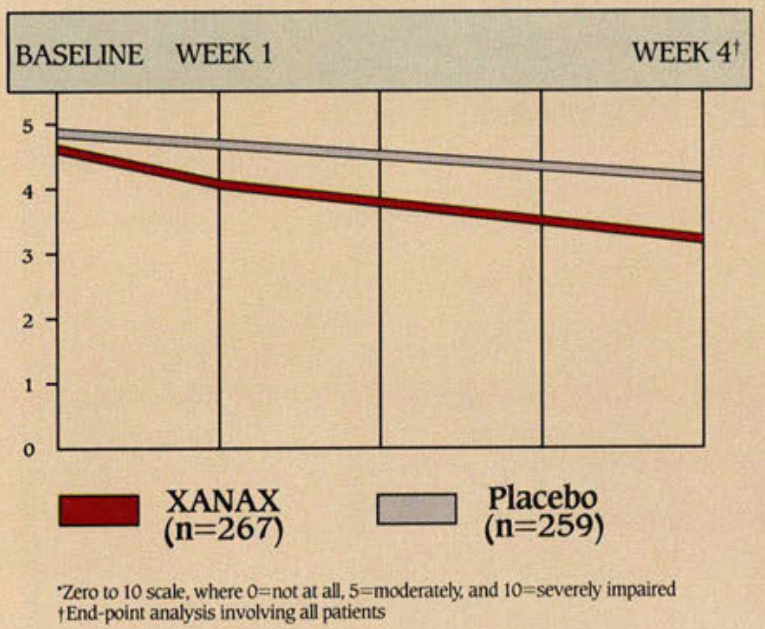

Please see last page for references and brief summary of prescribing information.

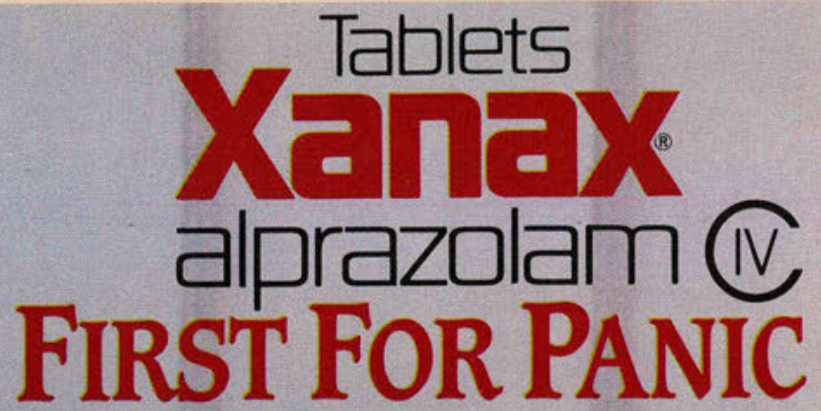




\section{PANIC DISORDER}

\section{PROPER DOSING}

The usual starting dose for panic patients is $0.5 \mathrm{mg}$ t.i.d. Depending on the patient's response, the dose can then be adjusted upward in increments no greater than $1 \mathrm{mg}$ every 3 to 4 days to a maximum of $10 \mathrm{mg} /$ day. Some patients may require a slower dosage titration. In clinical studies, the average daily dose after 8 weeks was $5.7 \mathrm{mg}$. The risk of dependence and its severity appear to be greater in patients treated with relatively high doses (above $4 \mathrm{mg} /$ day) and for long periods (more than 8 to 12 weeks), as required by panic patients.

Continue incremental dosage adjustment until adequate control of panic attacks is achieved and phobic symptoms are reduced.

\section{SIDE EFFECTS}

Most treatment-emergent symptoms and side effects reported by patients who received XANAX Tablets were those generally associated with benzodiazepine therapy, such as drowsiness/sedation and ataxia/impaired coordination. At least mild sedation was reported by $77 \%$

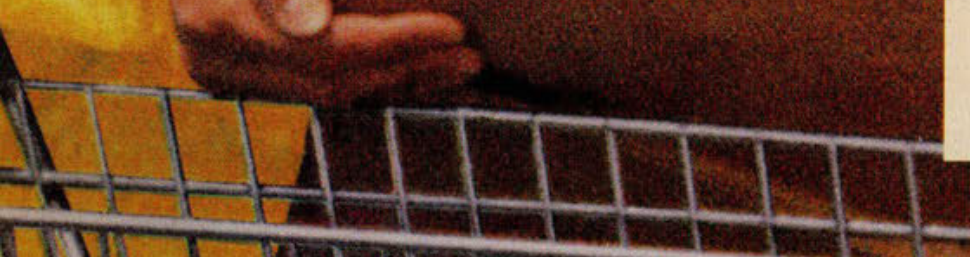




\section{F XANAX : ESSENTIAL TO SUCCESS}

of patients who received therapy with XANAX Tablets and by $43 \%$ of patients who received placebo. Side effects are generally observed at the beginning of therapy and usually disappear upon continued medication or decreased dosage.

\section{MAINTENANCE AND TAPERING}

The necessary duration of treatment for panic-disorder patients responding to XANAX is unknown. After a period of extended freedom from attacks, a carefully supervised, tapered discontinuation may be attempted. Dosage reduction must be individualized according to patient response, and the length of time will depend in part on the dosage level attained. There is evidence that discontinuation may be exceedingly difficult for some patients to accomplish without recurrence of panic-disorder symptoms or the development of withdrawal phenomena.

Dosage should be reduced gradually, never abruptly, by not more than $1 \mathrm{mg} /$ week until a total daily dose of
$4 \mathrm{mg}$ is achieved; by $0.5 \mathrm{mg} /$ week until a total daily dose of $2 \mathrm{mg}$ is reached; and by $0.25 \mathrm{mg} /$ week thereafter. Some patients may require an even slower tapering of dosage. Withdrawal reactions may occur when dosage reduction occurs for any reason. This not only includes purposeful tapering but also inadvertent reduction of dose. Therefore, the dosage of XANAX should be reduced or discontinued gradually.

\section{NEW XANAX 2-mg TABLETS FOR PANIC}

- Greater convenience in maintenance dosages

- Scored to allow incremental dosing $(0.5 \mathrm{mg}$, $1 \mathrm{mg}$, or $2 \mathrm{mg}$ )

- New tablet strength more economical for patients

Please see last page for references and brief summary of prescribing information.

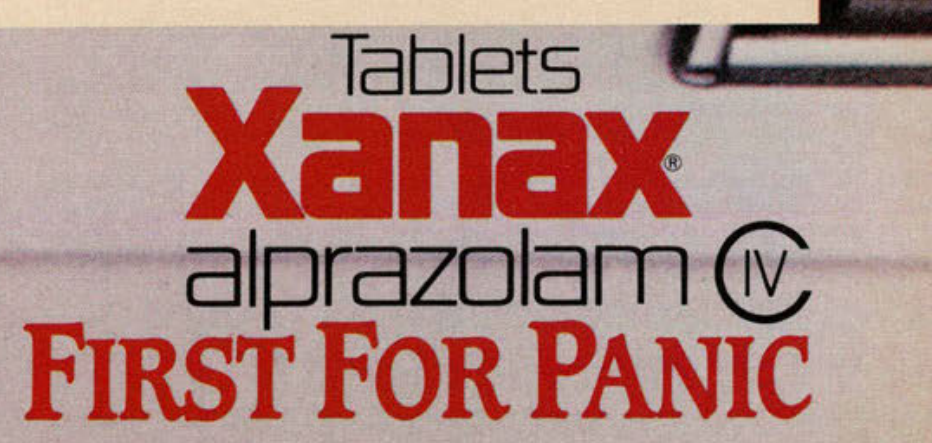




\section{XANAX ${ }^{5}$ Tablets}

\section{(alprazolam, @ Upjohn)}

INDICATIONS AND USAGE

Generalized anxiety disorder, short-term relief of the symptoms of anxiety, and anxiety associated with depression. Anxiety or tension associated with the stress of everyday life usually does not require an anxiolytic.

Panic disorder, with or without agoraphobia.

Effectiveness has been established for up to 4 months for anxiety disorder and 4 to 10 weeks for panic disorder; but panic disorder has been treated open label for up to 8 months with no apparent loss of benefit. The usefulness should be reassessed periodically.

\section{CONTRAINDICATIONS}

Sensitivity to XANAX or other benzodiazepines and in acute narrow-angle glaucoma

\section{WARNINGS}

\section{Dependence and withdrawal reactions, including seizures}

Physical dependence to XANAX can produce certain adverse clinical events, some life-threatening. These include a spectrum of withdrawal symptoms-the most important is seizure. Even after relatively short-term use at 0.75 to $4 \mathrm{mg}$ per day, there is some risk of dependence; but the risk and severity seem to be greater in patients treated with doses above $4 \mathrm{mg} /$ day for more than 8 to 12 weeks

\section{Treatment of panic disorder: Dose and risks of XANAX}

Panic-disorder patients often need doses greater than $4 \mathrm{mg} /$ day, hence the risk of dependence may be greater than in patients treated for less severe anxiety. Based on studies involving 641 patients, the most frequent symptoms seen during discontinuation were:

Neurologic: Insomnia, light-headedness, abnormal involuntary movement, headache, muscular twitching, impaired coordination, muscle-tone disorders, weakness.

Psychiatric: Anxiety, fatigue and tiredness, irritability, cognitive disorder, memory mpairment, depression, confusional state.

Gastrointestinal: Nausea/vomiting, diarrhea, decreased salivation

Other systems: Weight loss, decreased appetite, sweating, tachycardia, blurred vision. It has not yet been determined if these symptoms are clearly related to dose and duration of therapy. In two controlled trials of the discontinuation of XANAX lasting 6 to 8 weeks, $71 \%$ to $93 \%$ of patients treated with XANAX compared with $89 \%$ to $96 \%$ of placebo patients tapered completely off medication. The ability of patients to completely discontinue after long-term therapy has not been reliably determined.

Seizures were reported in 8 of 1,980 patients who took more than $4 \mathrm{mg}$ XANAX daily for over 3 months, generally during abrupt dose reduction. There have been occasional reports of seizures during gradual taper; the risk seems to be greatest 24 to 72 hours after discontinuation.

Status epilepticus and its treatment: Discontinuation of XANAX has been associated with seizures. In most cases a single seizure was reported; however, multiple seizures and status epilepticus have been reported. Treatment is the same as that for status of any cause.

Interdose symptoms: Early morning anxiety and emergence of anxiety symptoms between doses have been reported in panic patients taking XANAX. It can usually be managed with more frequent administration of the same total daily dose or by increasing total dosage.

Risks of dose reduction: Withdrawal reactions may occur with dosage reduction for any reason; dosage should be reduced gradually. (See DOSAGE AND ADMINISTRATION.)

XANAX is not of value in treating psychosis and should not be used in lieu of appropriate treatment. Patients receiving XANAX should be cautioned about hazardous occupations or activities requiring full alertness and also about simultaneous ingestion of alcohol or other CNS depressants.

Benzodiazepines can cause fetal harm in pregnant women, hence women who may become pregnant should be warned. Avoid during the first trimester. (See DRUG ABUSE AND DEPENDENCE and DOSAGE AND ADMINISTRATION.)

\section{PRECAUTIONS}

General: If XANAX is combined with other psychotropics or anticonvulsants, consider drug potentiation. (See DRUG INTERACTIONS.) Use the usual precautions in patients with impaired renal, hepatic, or pulmonary function and regarding prescription size in depressed and suicidal patients. Use the smallest effective dose to avoid ataxia or oversedation, which may be a particular problem in elderly or debilitated patients. Alprazolam plasma half-life may be prolonged in obese patients or those with alcoholic liver disease. There have been rare reports of death in patients with severe pulmonary disease shortly after the start of therapy with XANAX. Episodes of mania and hypomania have been reported in depressed patients. Alprazolam is weakly uricosuric.

Information for patients: For all users of XANAX. Alert patients about: (1) consumption of alcohol and drugs, (2) not taking any benzodiazepine during pregnancy or while nursing, (3) operating machinery or driving, (4) not increasing the dose due to risk of dependence, (5) not stopping the drug abruptly.

Additional advice for panic patients:

Use of more than $4 \mathrm{mg}$ per day of XANAX for long periods of time may cause severe emotional and physical dependence in some patients, and these patients may find it difficult to stop treatment. In two studies lasting 6 to 8 weeks, $7 \%$ to $29 \%$ of patients treated with XANAX did not completely taper off therapy. The ability of patients to completely discontinue therapy has not been determined. Also, extended use of high doses appears to increase the incidence and severity of withdrawal reactions when XANAX is discontinued. These are generally minor, but seizure, which can be life-threatening, can occur, especially if dose is reduced too rapidly or stopped abruptly.

Laboratory tests: Not ordinarily required in otherwise healthy patients.

Drug interactions: Additive CNS depressant effects with other psychotropics, anticonvulsants, antihistamines, ethanol, and other CNS depressants. Plasma levels of imipramine and desipramine are increased. Pharmacokinetic interactions with other drugs have been reported. Cimetidine and oral contraceptives can delay clearance of benzodiazepines. Drug/laboratory test interactions: No consistent pattern. Carcinogenesis, mutagenesis, impairment of fertility: No carcinogenic potential or impairment of fertility in rats. Pregnancy: See WARNINGS. Nonteratogenic effects: The child born of a mother on benzodiazepines may be at some risk for withdrawal symptoms, neonatal flaccidity, and respiratory problems. Labor and delivery: No established use. Nursing mothers: Benzodiazepines are excreted in human milk. Women on XANAX should not nurse. Pediatric use: Safety and effectiveness in children below the age of 18 have not been established.

\section{ADVERSE REACTIONS}

Side effects are generally observed at the beginning of therapy and usually disappear with continued medication. In the usual patient, the most frequent side effects are likely to be an extension of the pharmacologic activity of XANAX, eg, drowsiness or light-headedness
Central nervous system: Drowsiness, light-headedness, depression, headache, confusion, insomnia, nervousness, syncope, dizziness, akathisia, and tiredness/ sleepiness. Impaired coordination, irritability, memory impairment, cognitive disorder, dysarthria, anxiety, abnormal involuntary movement, changed libido, muscular twitching, weakness, muscle-tone disorders, agitation, disinhibition, paresthesia talkativeness, vasomotor disturbances, derealization, dream abnormalities, fear feeling warm.

Gastrointestinal: Dry mouth, constipation, diarrhea, nausea/vomiting, increased salivation, decreased salivation, and abdominal distress.

Cardiorespiratory: Tachycardia/palpitations, hypotension, nasal congestion, chest pain, hyperventilation, upper respiratory infection.

Other: Blurred vision, rigidity and tremor, tinnitus, muscular stiffness and cramps, sweating, skin disorders, rash, change in appetite, micturition difficulties, menstrual disorders, sexual dysfunction, edema, incontinence, infection, dermatitis/allergy, weight gain, and weight loss.

Withdrawal seizures with rapid decrease or abrupt discontinuation. (See

WARNINGS.)

To discontinue treatment, dosage must be reduced slowly by no more than 0.5 mg every 3 days.

The following adverse events have been reported with benzodiazepines: dystonia concentration difficulties, anorexia, slurred speech, jaundice, pruritus, diplopia.

Untreated panic disorder has been associated with depressive disorders and suicide. When treating panic patients, the same caution must be used as in treating patients with depression or suicidal ideation.

Paradoxical reactions such as stimulation, agitation, rage, increased muscle spasticity, sleep disturbances, and hallucinations may occur. Should these occur, discontinue the drug.

During prolonged treatment, periodic blood counts, urinalysis, and blood chemistry analysis are advisable. Minor EEG changes, of unknown significance, have been observed.

Liver enzyme elevations, gynecomastia, and galactorrhea have been reported, but no causal relationship was established.

\section{DRUG ABUSE AND DEPENDENCE}

Physical and psychologic dependence: Withdrawal symptoms like those noted with sedative/hypnotics and alcohol have been seen after discontinuance of benzodiazepines. Symptoms can range from mild dysphoria and insomnia to a major syndrome including abdominal and muscle cramps, vomiting, sweating, tremors, and convulsions. The distinction between withdrawal symptoms and recurrence of illness is difficult. Withdrawal typically includes new symptoms, occurs toward the end of taper or shortly after discontinuation, and decreases with time. Recurrent panic disorder recurs early or late, with persistent symptoms similar to the initial presentation. When necessary XANAX should be restarted in adequate dosage. Withdrawal symptoms, including seizures, may occur after brief therapy with doses of 0.75 to $4 \mathrm{mg} /$ day, but severity and incidence are apparently increased after doses above $4 \mathrm{mg} / \mathrm{day}$, after rapid decrease of dosage or abrupt discontinuation. Dosage should be gradually tapered under close supervision, especially in patients with a history of seizures or epilepsy.

Psychologic dependence is a risk with all benzodiazepines, increasing at higher doses, with long-term use, and in patients with a history of alcohol or drug abuse. Addiction-prone patients should be closely supervised when receiving XANAX and repeat prescriptions limited.

Controlled Substance Class: XANAX is a controlled substance and has been assigned to schedule IV.

\section{OVERDOSAGE}

Manifestations include somnolence, confusion, impaired coordination, diminished reflexes, and coma. Death has been reported with overdosage of benzodiazepines by themselves or in combination with overdosage of alcohol.

\section{DOSAGE AND ADMINISTRATION}

Dosage should be individualized, using the lowest effective dose. The need for treatment should be reassessed frequently

Anxiety: The usual starting dose is .25 to $0.5 \mathrm{mg}$ ti.d. Maximum daily dose is $4 \mathrm{mg}$. Patients who are elderly or debilitated, or have advanced liver disease, may be especially sensitive to benzodiazepines, and the starting dose is $0.25 \mathrm{mg}$ b.i.d. or ti.d. Reduce dosage gradually, by no more than $0.5 \mathrm{mg}$ every 3 days, or more slowly.

Panic disorder: Many patients required more than $4 \mathrm{mg}$ daily. Mean dosage in studies was 5 to $6 \mathrm{mg} /$ day, with a maximum of $10 \mathrm{mg} /$ day. Treatment may be initiated with $0.5 \mathrm{mg}$ t.i.d. Depending on the response, dose may be increased every 3 or 4 days by up to $1 \mathrm{mg}$ daily. After extended freedom from attacks, dosage should be carefully tapered by, at most, $0.5 \mathrm{mg}$ every 3 days. Some patients may be resistant to all discontinuation regimens.

\section{HOW SUPPLIED}

XANAX Tablets are available in 0.25-mg, 0.5-mg, 1-mg, and 2-mg strengths.

CAUTION: FEDERAL LAW PROHIBITS DISPENSING WITHOUT PRESCRIPTION.

\section{References:}

1. Regier DA, Boyd JH, Burke JD Jr, et al. One-month prevalence of mental disorders in the United States: based on five epidemiologic catchment area sites. Arch Gen Psychiatry. 1988;45:977-986.

2. American Psychiatric Association. Diagnostic and Statistical Manual of Mental Disorders, Third Edition, Revised. Washington, DC. American Psychiatric Association; 1987:236-238

3. Ballenger JC, Burrows GD, DuPont RL Jr, et al. Alprazolam in panic disorder and agoraphobia: results from a multicenter trial, I: efficacy in short-term treatment. Arch Gen Psychiatry. 1988;45:413-422. 


\section{Why this publication and more than 1,300 others let us go over their books}

\section{once a year.}

Some publications, we're sorry to say, keep their readers undercover. They steadfastly refuse to let BPA (Business Publications Audit of Circulation, Inc.) or any other independent, not-for-profit organization audit their circulation records.

On the other hand, over 1,300 publications (like this one) belong to BPA. Once a year, BPA auditors examine and verify the accuracy of our circulation records.

The audit makes sure you are who we say you are. The information helps advertisers to determine if they are saying the right thing to the right people in the right place.

It also helps somebody else important: you. Because the more a publication and its advertisers know about you, the better they can provide you with articles and advertisements that meet your information needs.

BPA. For readers it stands for meaningful information. For advertisers it stands for meaningful readers. Business Publications Audit of Circulation, Inc. 360 Park Ave. So., New York, NY 10010. 